
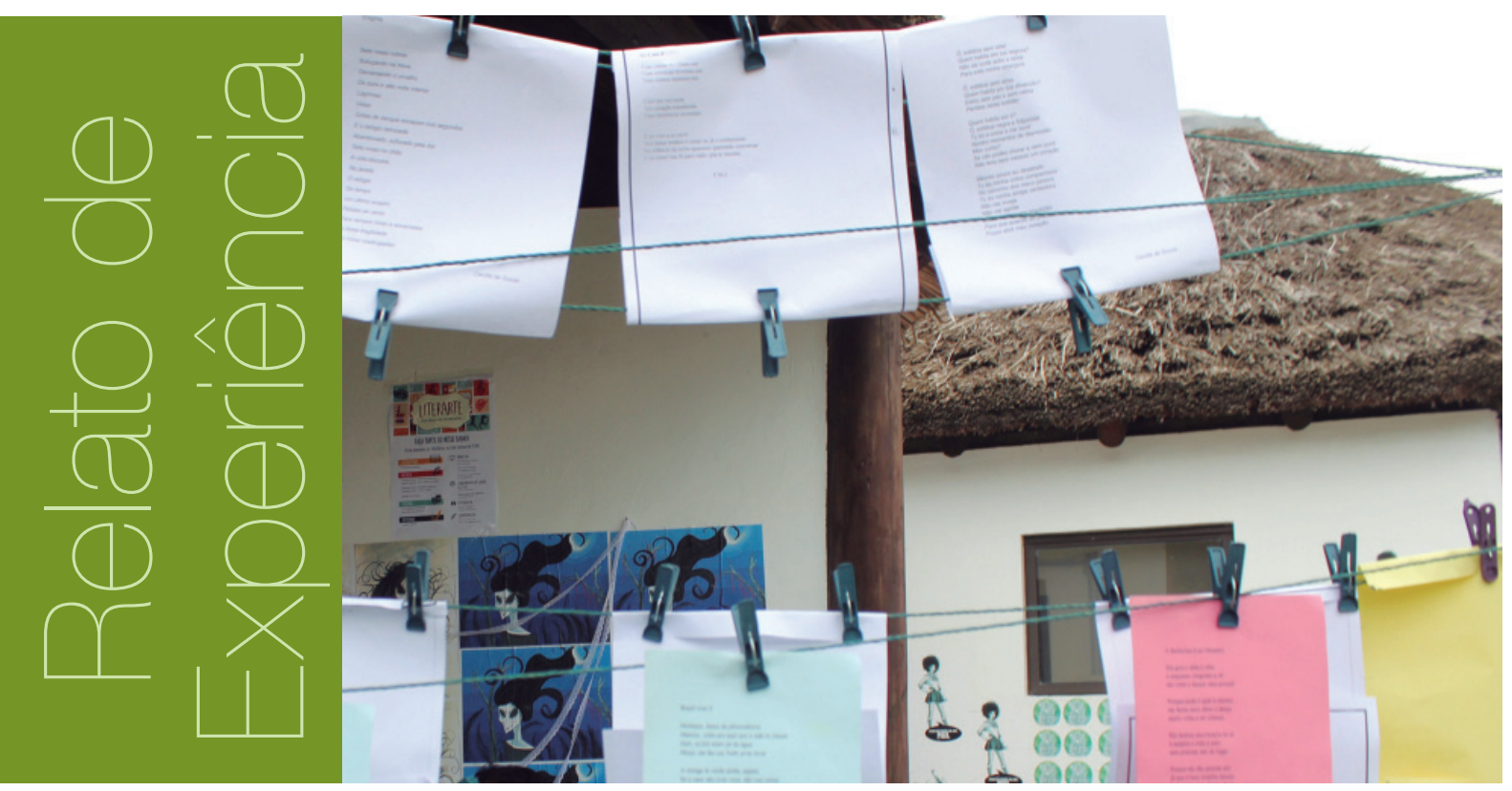

\title{
Sarau Literarte: a socialização da leitura e da arte
}

\author{
Lisiane Ferreira de Lima - lisi.lima.rg@hotmail.com \\ Twyne Soares Ramos² - twyneramos@yahoo.com.br
}

\section{RESUMO}

0 presente trabalho visa relatar a experiência com o desenvolvimento do projeto de extensão "Literarte: literatura em movimento", que está vinculado a um projeto de maior abrangência, intitulado "Socializando a leitura", desenvolvido pelo Instituto de Letras e Artes, da Universidade Federal do Rio Grande (FURG). 0 projeto envolve literatura e outras artes, como dança, desenho, fotografia, música e teatro.

\section{PALAVRAS-CHAVE}

Sarau. Literatura. Socialização da leitura. FURG.

\section{ABSTRACT}

This paper aims to describe the experience of organizing the extension project "Literarte: literature em movimento", which is linked to a more extensive project called "Socializando a leitura", developed by the Instituto de Letras e Artes of the Universidade Federal do Rio Grande (FURG). The project encompasses literature and other forms of art, such as dancing, drawing, photography, music and theater.

\section{KEYWORDS}

Literary soiree. Literature. Socialization of Reading. FURG.

\section{Relato de experiência}

Este trabalho apresenta e discute os resultados do projeto de extensão "Literarte: literatura em movimento", que envolve a área da Literatura, e outras artes, como dança, desenho, fotografia,

\footnotetext{
1 Mestranda do Programa de Pós-Graduação em Letras - História da Literatura, da Universidade Federal do Rio Grande. Bolsista CAPES.

2 Mestranda do Programa de Pós-Graduação em Letras - História da Literatura, da Universidade Federal do Rio Grande. Bolsista CAPES.
} 
música e teatro. As atividades são coordenadas pelos professores Artur Emílio Alarcon Vaz e Mairim Link Piva e pelas mestrandas Lisiane Ferreira de Lima e Twyne Soares Ramos, vinculados à Universidade Federal do Rio Grande (FURG). Inicialmente, o projeto promove saraus, realizados no espaço Café Cultural, da FURG e, posteriormente, visa ser realizado em outros locais, promovendo a socialização da literatura e de outras artes.

Ao refletirmos sobre a arte e a literatura no contexto contemporâneo, pensamos no quanto é importante despertar o prazer da leitura, pois ela é capaz de ampliar a consciência, a criticidade e a sensibilidade do sujeito frente ao mundo em que vive. Segundo James Paul Gee (2004), a leitura envolve, também, o processo cultural. Ainda que necessite de uma instrução estruturada, ou seja, a decodificação das letras, a leitura de textos é uma experiência prática e contínua que nos permite obter um conhecimento de nós mesmos e do mundo através do olhar do outro. A linguagem é o ponto que entremeia a relação de conhecimento entre nós e 0 outro.

A partir desse pressuposto, os projetos de extensão, na área de literatura e leitura, desenvolvidos pelo Instituto de Letras e Artes (ILA), da FURG, organizam-se em função de diferentes ações que buscam propiciar cursos de formaç̧ão para professores da rede pública. Com isso, qualificando e multiplicando o conhecimento sobre o mundo da leitura e sobre formas de incentivo ao ato de ler para os alunos de Ensino Fundamental e Ensino Médio. Além disso, os projetos promovem atividades de incentivo à leitura diretamente para alunos de escolas públicas e comunidade em geral, além de levar aos leitores a possibilidade de trocar livros.

Nessa medida, surge a proposta de ampliação do projeto "Socializando a leitura" para um novo viés, dando início ao projeto de extensão "Literarte: literatura em movimento". Tal projeto é um desdobramento das múltiplas ações de extensão sobre arte e literatura oferecidas dentro da FURG (Fig.1).

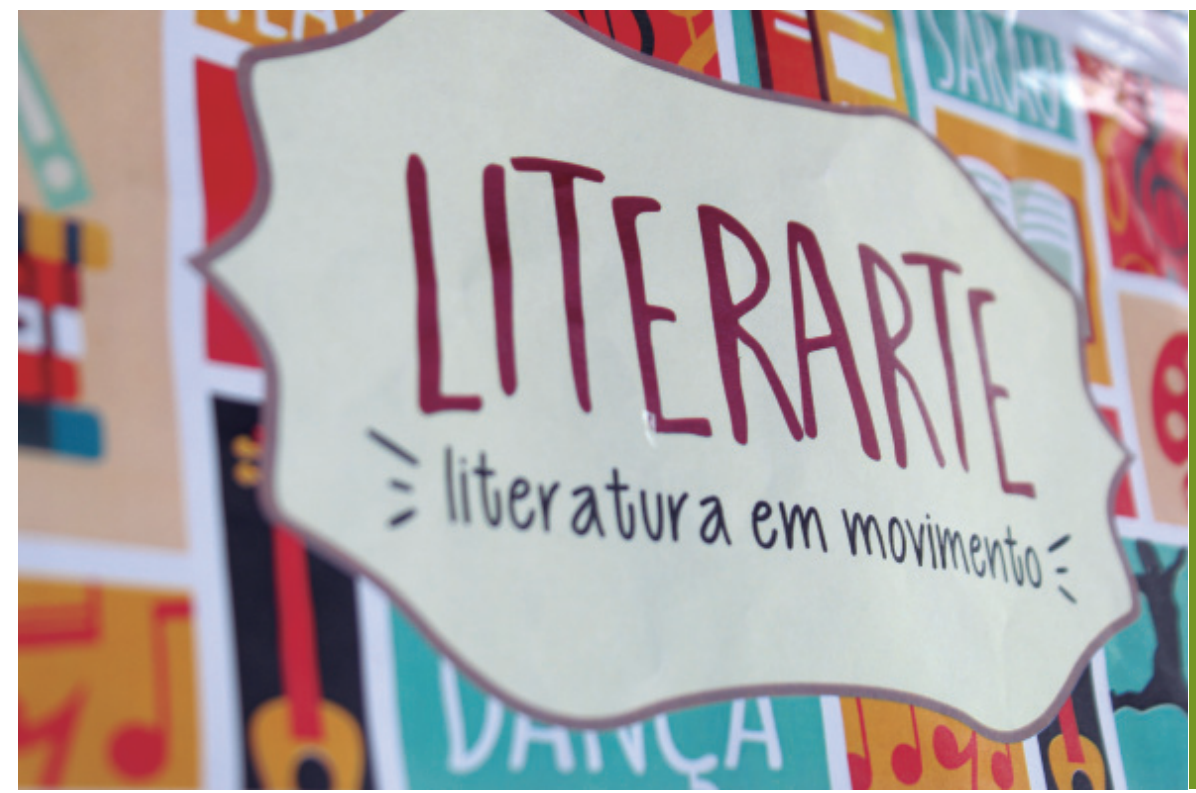

Figura 1: Identidade visual do Literarte, por Marco Müller.

Fonte: Foto de Natalie Piragine.

Na esfera de cursos de extensão, mostra-se como uma ampliação de cursos como "Literatura: leituras e ensino", das experiências do curso "Literatura sul-rio-grandense contemporânea", do "Conto sul-rio-grandense contemporâneo" e do curso "0 imaginário nos contos de fadas". Além disso, o atual projeto dialoga com a "Oficina de contação: a formação de leitores" e com 0 projeto "Troca de livros", cujas presenças vêm se ampliando no Município de Rio Grande.

Sabemos que a Literatura é uma das áreas de destaque na formação do profissional de Letras, constituindo, inclusive, diversas linhas de pesquisa dos cursos de graduação e Pós-graduação do Instituto de Letras e Artes, da FURG. Ademais, a ampliação de conhecimentos e a reflexão sobre os caminhos da literatura contemporânea e da produção escrita como processo são pertinentes para a atuação de mediadores de leitura na contemporaneidade. Por este motivo, a proposta atual tem caráter extensionista, pois além de direcionada ao meio acadêmico, está aberta para profissionais de diversas áreas da educação e mesmo para a comunidade em geral. 
Sendo assim, o projeto 'Literarte: literatura em movimento' justifica-se, também, pela sua abrangência social e artística, uma vez que promove um encontro entre artistas e admiradores da arte da universidade e da comunidade em geral. 0 projeto possibilita, além da visibilidade a autores consagrados pela crítica literária, a difusão de textos autorais dos participantes do sarau. Além disto, destaca-se 0 fato de que o sarau encontra-se aberto durante sua realização caso os espectadores desejem participar de variadas formas, objetivando a interação entre as artes e a cultura.

Para Paulo Freire, ler não é caminhar sobre as letras, mas interpretar o mundo e poder lançar sua palavra sobre ele, interferir no mundo pela ação. Ler é tomar consciência. A leitura é antes de tudo uma interpretação do mundo em que se vive. É também representá-lo pela linguagem escrita, falar sobre ele e o interpretar.

Ler, dentro desta perspectiva, é também libertar-se. Apesar de sua importância, a leitura em nossa sociedade ainda encontra barreiras, seja no seu valor sociocultural ou no valor financeiro que 0 livro, seu instrumento, obtém no mercado. Assim, as ações propostas nesse projeto permitem que a comunidade possa tanto ampliar quanto socializar sua bagagem de cultura e arte. Deste modo, o projeto visa à interação entre a literatura e diferentes artes, contribuindo para desenvolvimento da leitura e funcionando como um espaço no qual a comunidade poderá acercar-se da arte e, inclusive, mostrar seus próprios trabalhos artísticos.

A primeira edição do "Literarte: literatura em movimento" ocorreu em novembro de 2015, na forma de um sarau que buscava incentivar a arte e a literatura, bem como movimentar o espaço Café Cultural, da FURG. Tivemos a participação de mais de 30 atividades, que envolveram desde obras de autores já canonizados e/ou de autoria dos próprios participantes do evento, além de apresentações musicais de voz, violão e violino e apresentação teatral, contando também com o lançamento de dois livros de acadêmicos da graduação e Pós-graduação da universidade. 0 palco de apresentações esteve aberto durante toda realização do sarau (Fig. 2).

Figura 2: I Literarte em andamento.

Fonte: Foto de Natalie Piragine.

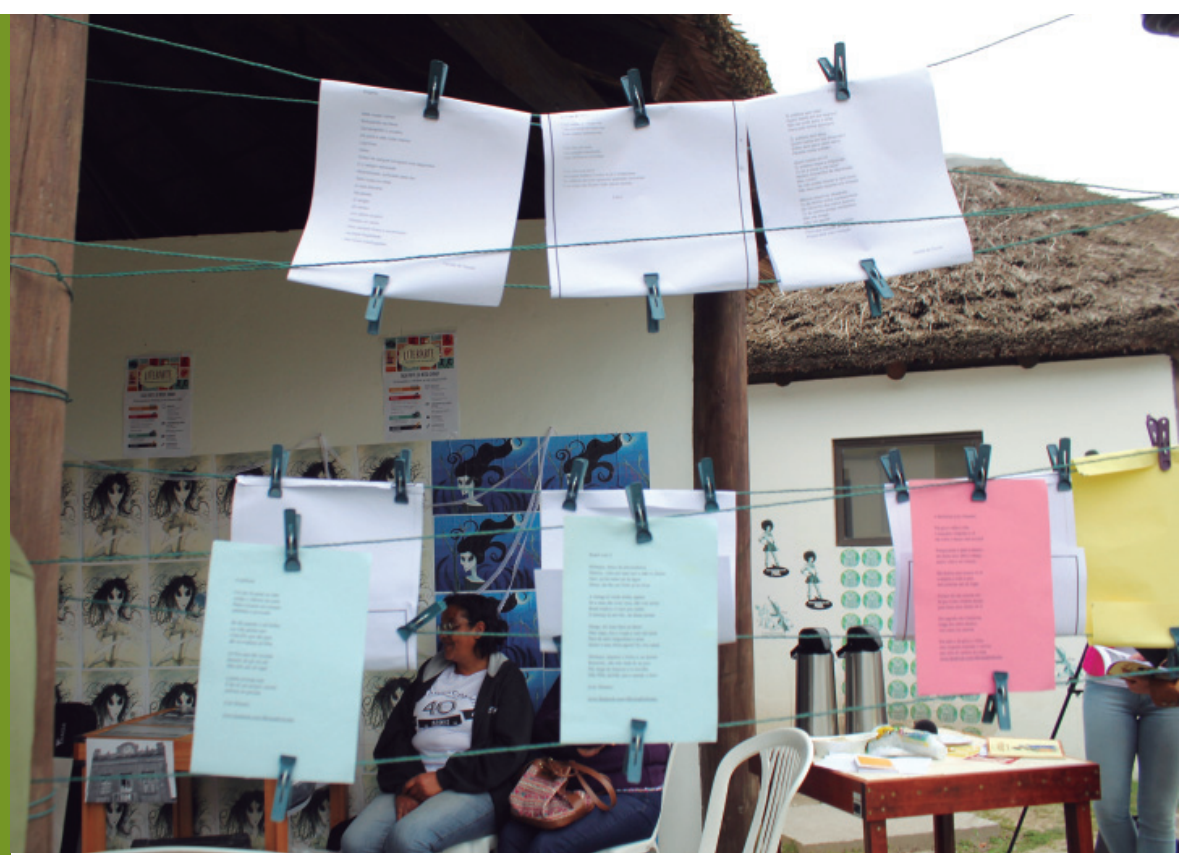

Desse modo, contamos com a participação da comunidade acadêmica e da comunidade em geral, bem como com os integrantes dos projetos "Socializando a leitura: troca de livros", "Oficina de contação: a formação do leitor" e "Conto Sul-rio-grandense Contemporâneo", que também fizeram parte da atividade. 0 que foi relatado, a todo o momento, pelos participantes do encontro, é que sentiam a falta de um espaço de interação artística, sendo exatamente o que o Literarte busca realizar. Na visão dos integrantes dos demais projetos de extensão que compuseram o evento, o mesmo tornou-se importante dentro das atividades do ano letivo, pois busca integrar todos os participantes, valendose da união de todos os trabalhos, tornando assim o Literarte um espaço que pode proporcionar a visibilidade dos resultados de cada ação. 
As atividades do sarau contemplaram diferentes artes e houve leitura de textos literários em língua inglesa, espanhola e portuguesa. A mobilização acadêmica foi expressiva e 0 público presente não era composto apenas por acadêmicos da universidade, mas também pela comunidade, de modo geral. Segundo Fernanda Machado Johannsen, participante do evento, o projeto "deve ser contínuo, com propostas temáticas diferenciadas a cada edição, acrescentando mais esse momento cultural e de integração artística no âmbito acadêmico, porque a arte e a literatura são instrumentos de inspiração de vida". Ressalta, além disto, que "há uma contribuição do projeto em expor os artistas e escritores da cidade, valorizando a arte e cultura produzidas em nosso município".

Durante 0 evento, intercalaram-se leituras de textos literários com outras atividades, dentre elas a apresentação de uma peça teatral, que ficou por conta dos integrantes do grupo "Oficina de contação: a formação de leitores" (Luciana Padovani, Ana Luisa Cosme, Bianca Barros, Lucas Dionizio, Myrelli Serra, Giulia Guadagnini) com a peça "A verdadeira história dos três porquinhos". No âmbito musical, houve apresentação de voz e violão, de Eduarda Pires e Fabiano Silva, e de voz, violão e violino, de Twyne Ramos, Henrique Meneses e André Soares (Fig. 3).

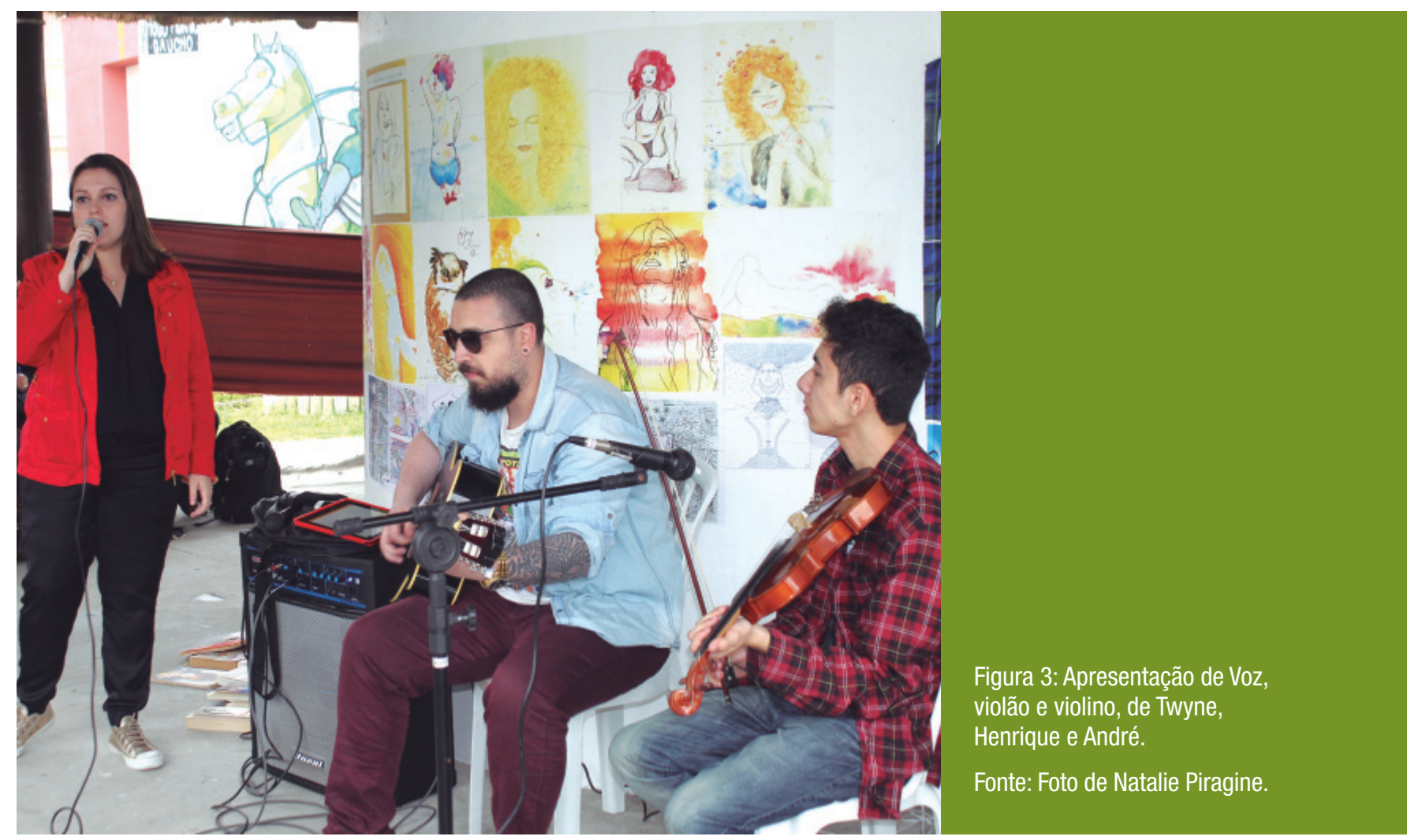

Além dessas atividades artísticas, foram lançados os livros Mas enfim, de Léo Ottesen, e África, prazer em conhecer!, organizado por Juliana Cruz. Houve, também, a participação das fotógrafas Natalie Piragine e Juliana Rodrigues, que fotografaram o evento; de Marco Müller, responsável pela identidade visual do Literarte e de Paula Liaroma, com a exposição de fotos do projeto "Ponto de Cultura ArtEstação". No encerramento do evento, tivemos a participação da Banda Tio Clóvis.

Interpretamos de forma muito positiva a realização e a repercussão da primeira edição do Sarau Literarte, pois todas as atividades previamente planejadas ocorreram de forma contempladora e 0 ânimo de quem participou enalteceu ainda mais a interação do evento, tornando-0 um espaço enriquecedor de trocas de experiências. Além disto, fomos prestigiados pelos núcleos de pesquisa e extensão da universidade, com o apoio da PROEXC - Pró-Reitoria de Extensão e Cultura, da Universidade Federal do Rio Grande (FURG), como também das equipes da FURG TV e Rádio, que fizeram a cobertura e divulgação do evento (Fig. 4) 
Figura 4: I Literarte

em andamento.

Fonte: Foto de

Natalie Piragine.

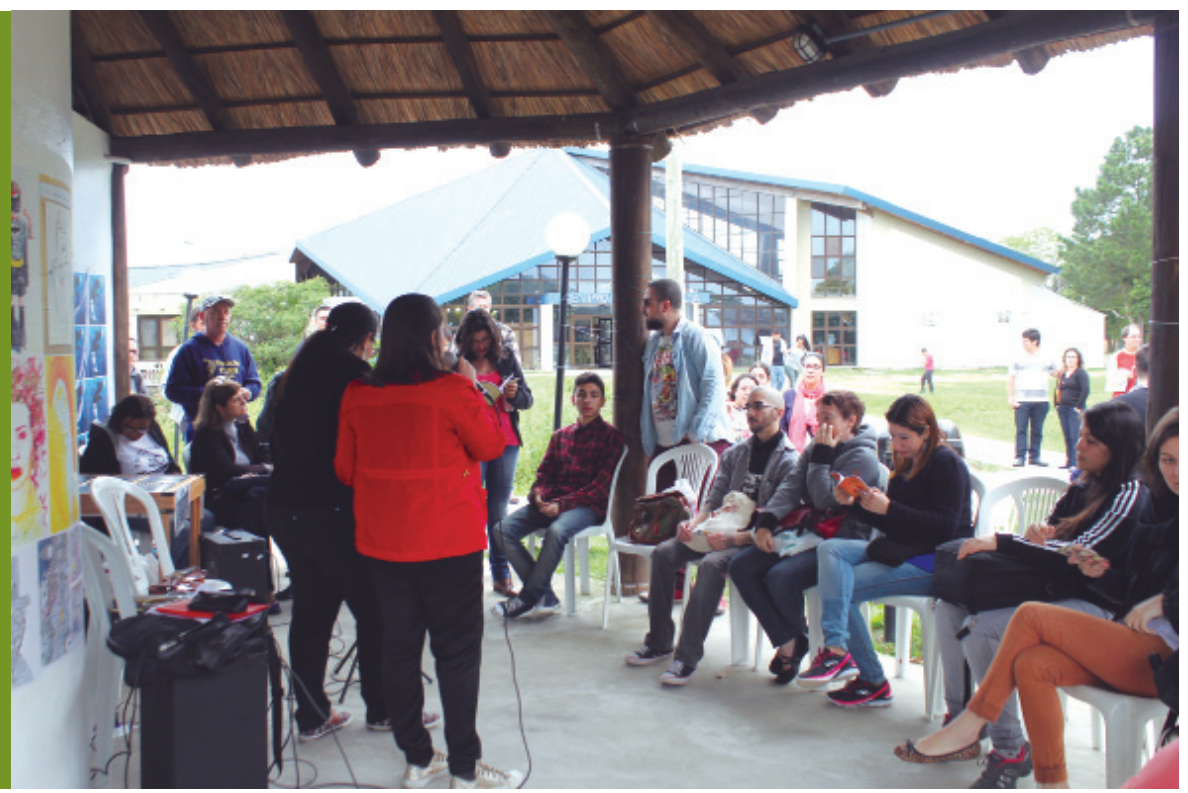

Em virtude da urgência de um espaço dentro do meio acadêmico que contemple e busque a integração de todas as artes, as próximas edições do Literarte já estão sendo organizadas, buscando desenvolver atividades temáticas, dando espaço e voz para os discentes, docentes e comunidade em geral.

Conforme afirma Antônio Candido, a leitura literária "confirma no homem aqueles traços que reputamos essenciais, como o exercício da reflexão, a aquisição do saber, a boa disposição para com o próximo, o afinamento das emoções, a capacidade de penetrar nos problemas da vida, o senso da beleza, a percepção da complexidade do mundo e dos seres, o cultivo do humor" (2004, p. 180). Assim, nosso maior objetivo é a socialização da arte e da cultura dentro do ciclo universitário, difundindo e celebrando a leitura e a arte.

\section{Referências}

BAPTISTA, Anna Maria Haddad. Literatura e Ensino: duas propostas para reflexão. Disponível em: http://www.uninove.br/PDFs/Mestrados/Educa\%C3\%A7\%C3\%A30/IIENCONTRO/AnaHaddad.pdf. Acesso em 02 de jan. de 2016.

BRAGA, Regina; SILVESTRE, Maria de Fátima. Construindo o leitor competente: atividades de leitura interativa para a sala de aula. São Paulo: Peirópolis, 2002.

CANDIDO, Antônio. Literatura e Sociedade: estudos de teoria e história literária. 7ª edição. São Paulo: Nacional, 1985.

Vários escritos. São Paulo/Rio de Janeiro: Duas cidades / Ouro sobre Azul, 2004.

COELHO, N.N. Literatura: arte, conhecimento e vida. São Paulo: Peirópolis, 2000.

FREIRE, Paulo. Pedagogia da autonomia: saberes necessários à prática educativa. São Paulo, Paz e Terra, 1996.

A importância do ato de ler: em três artigos que se completam.

50.ed. São Paulo: Cortez, 2009.

GEE, J. P. Situated language and learning: a critique of traditional schooling. London: Routledge, 2004. 